\title{
The role of anticitrullinated protein antibodies in the early stages of rheumatoid arthritis
}

\author{
Jacqueline Dekkers, René E.M. Toes, Tom W.J. Huizinga, \\ and Diane van der Woude
}

\begin{abstract}
Purpose of review
This review provides an update on the recent discoveries on the role of anticitrullinated protein antibodies (ACPA) in early rheumatoid arthritis (RA).
\end{abstract}

\section{Recent findings}

RA is characterized by an immune response against posttranslationally modified proteins, in particular citrullinated proteins. Recent studies have found that the ACPA response matures shortly before clinical disease manifests itself and is characterized by an increase in titre, isotype switching, antigen-recognition profile, and a change in the Fc-glycosylation pattern. To date, many citrullinated autoantigens have been identified and novel studies suggest that the human leucocyte antigen class II locus may directly influence the maturation of the ACPA response via antigen-specific T cells. Clinical studies have demonstrated that effective treatment of arthritis can lead to reduced ACPA levels or a change in composition of ACPA. In addition to ACPA, autoantibodies targeting other posttranslational modifications have been identified and may be associated with disease prognosis.

\begin{abstract}
Summary
Key studies have demonstrated that autoimmunity against citrullinated proteins is already present in preclinical RA and matures over time. Future studies are required to reveal whether autoantibodies and the $\mathrm{B}$ cells that produce them play a role in disease development or can function as biomarkers for disease maturation.

Keywords

anticitrullinated protein antibodies producing B cells, antibodies to citrullinated protein antigens, autoantibodies, rheumatoid arthritis
\end{abstract}

\section{INTRODUCTION}

The identification of anticitrullinated protein antibodies (ACPA) has had a major impact on the understanding of rheumatoid arthritis (RA). In the late 1990s, it was described for the first time that RA patients produce autoantibodies that target peptides and proteins containing citrulline, a modified form of the amino-acid arginine [1,2]. Citrullination is a posttranslational modification of protein-bound arginine into citrulline residues which is mediated by peptidyl arginine deiminase (PAD) enzymes and is essential for the generation of antigens recognized by ACPA [3]. Although the physiological role of citrullination is not precisely known, it is clear that this protein modification can occur during a variety of biological processes, including inflammation. Following the identification of citrullinated proteins, several diagnostic tests were developed based on cyclic citrullinated peptides (CCP) as a test substrate for detecting ACPA. Using the CCP-assay, a highly reliable diagnostic tool became available for routine testing of antibodies directed against citrullinated epitopes in early RA patients.

The presence of ACPA in the sera of patients represents an important early biomarker and has been added to the 2010 American College of Rheumatology/European League Against Rheumatism (ACR/EULAR) classification criteria for RA [4]. The selected parameters in the 2010 classification

\footnotetext{
Department of Rheumatology, Leiden University Medical Center, Leiden, The Netherlands

Correspondence to Jacqueline Dekkers, MD, Department of Rheumatology, C1-R, Leiden University Medical Center, Albinusdreef2, PO Box 9600, 2300 RC Leiden, The Netherlands. Tel: +31 71526 1255; e-mail: j.s.dekkers@lumc.nl
}

Curr Opin Rheumatol 2016, 28:000-000

DOI:10.1097/BOR.0000000000000277 


\section{KEY POINTS}

- Anticitrullinated protein antibodies (ACPA) can be detected several years before disease onset and mature over time with isotype switching and epitope spreading occurring in the preclinical phase of disease.

- The specific association of ACPA-positive RA with predisposing HLA alleles has fuelled hypotheses about the involvement of citrulline-specific $T$ cells in RA pathogenesis.

- Autoantibodies in RA patients have now also been found to recognize other posttranslational modifications such as homocitrulline and malondialdehydeacetaldehyde.

criteria were designed to include early markers of disease rather than established clinical features as was the case in the 1987 ACR guidelines. The ACPA serology enables the clinician to identify recent-onset RA patients earlier, which is crucial for achieving timely control of disease progression. Using the ACPA test it is possible to distinguish two subclasses RA patients: ACPA-positive and ACPAnegative. When comparing these two subclasses of RA, major differences have been observed regarding genetic and environmental risk factors, progression, remission, and response to treatment. In this review, we will provide an update on the latest findings concerning the ACPA maturation profile, the association between RA and the human leucocyte antigen (HLA) DR-locus, and the hypotheses about disease pathogenesis that contribute to a greater understanding of the role of ACPA in early RA.

\section{AUTOIMIMUNITY RELATED TO RHEUMATOID ARTHRITIS IS PRESENT LONG BEFORE ONSET OF CLINICAL SYMPTOMS}

Autoantibodies are an important hallmark of RA and several classes of autoantibodies have been described that precede the development of RA, including ACPA, rheumatoid factor and the recently identified anticarbamylated protein antibodies $\left[5-7,8^{*}\right]$. Especially ACPA are of particular interest as these autoantibodies are highly specific for RA and can be found in about $50 \%$ of early RA patients. The fact that ACPA are quite rare in healthy individuals, suggests that autoantibody-positive healthy individuals are at an increased risk of developing RA [9"']. These findings suggest that ACPA and/or the underlying B-/T-cell responses play a prominent role in disease pathogenesis. Shortly before clinical onset of disease, there appears to be maturation of the ACPA response which is characterized by an increase in ACPA titre, isotype switching, an increased antigen-recognition profile, and a change in Fc glycosylation pattern [10-14,15"']. Different observations strongly suggest that the development of ACPA-positive RA is based on a two-hit model. Environmental triggers and epigenetic stochastic events are thought to play a role in the initial break of tolerance leading to the formation of ACPA. A 'second hit', such as an infection or other factors, triggers the expansion of the ACPA response, which occurs relatively short before disease manifestation [16"]. Epidemiological studies have indicated that the HLA molecules do not play a considerable role during the first hit, but mainly contribute to the second hit that enables the expansion of the ACPA response.

ACPA can recognize a variety of citrullinated antigens, including type II collagen, fibrinogen, vimentin and many other citrullinated proteins. An increase or shift of the antigen-recognition profile, epitope spreading, can be a sign of maturation of the antibody response and disease progression. Epitope spreading is a hallmark of maturation of the ACPA response and is predictive for disease progression to early RA. After disease onset, the increased citrullinated epitoperecognition profile stabilizes and does not change anymore [10]. A recent 2-year follow-up study [17"-] enrolling 316 early RA patients in a Swedish pharmacotherapy trial suggested that disappearance of particular ACPA reactivities may be associated with a good treatment response in early RA. These results differ from previous reports in which the ACPA fine specificity did not seem to correlate with disease activity, progression, or response to therapy [18-20].

In the case of the response against recall antigens, antibodies undergo class switching, somatic hypermutation and affinity maturation to improve the immune reaction against the antigen.

The variable region of ACPA has undergone extensive somatic hypermutation, indicative of a T-cell-dependent B-cell response [21]. The avidity maturation of ACPA, however, appears to be different from recall antigens. As compared with antibodies against recall antigens, ACPA display a considerably lower avidity and the ACPA response shows only limited avidity maturation over time $[22,23]$. The presence of these low-avidity ACPA in RA patients is associated with a higher rate of joint destruction. ACPA can activate the complement system and can therefore play a role in the complement-mediated recruitment of inflammatory cells [24], which suggests that ACPA could be directly involved in the disease process. Moreover, 
ACPA-immune complexes combined with IgM or IgA rheumatoid factor can directly trigger Fc $\gamma$ receptors on macrophages and mast cells leading to the production of proinflammatory cytokines which contribute to RA synovitis $\left[25^{\circ}, 26^{\prime \prime}\right]$.

Maturation of antibody responses leads to a shift in isotype which enables the activation of other immune effector mechanisms. ACPA can use multiple isotypes, and these ACPA isotypes are already present before onset of RA [27]. In addition, the number of different ACPA isotypes is predictive for the development of radiological damage [28]. Similarly to the epitope-recognition profile, the ACPA isotype profile appears not to expand anymore during disease progression, indicating that maturation of the ACPA response takes place before onset of arthritis.

As mentioned above, the fragment crystallizable (Fc) region of an antibody interacts with Fc receptors of immune effector cells and the complement system, and thus determines which immune effector mechanisms can be recruited by the antibody. The glycosylation of the IgG-Fc region of ACPA has been reported to be different from non-ACPA IgG. The Fc region of ACPA-IgG contains reduced numbers of sialic acid and galactose residues [29], a feature which is generally considered to render IgG antibodies proinflammatory [30"]. The changes in ACPA Fc glycosylation pattern become more prominent around 3 months before onset of RA [15"']. Differences in glycosylation pattern between Ig isotypes might influence their affinity for Fc receptors. A recent study [30"] showed that ACPA-IgG $\mathrm{G}_{1}$ has a different Fc-glycan profile compared with non-CCP2 reactive $\operatorname{IgG}_{1}$, a particularity which can influence the affinity of ACPA IgG to Fc receptors and complement and may modulate ACPA effector and immuneregulatory functions [31].

In conclusion, all these different autoantibody characteristics evolve and mature before disease onset, and once patients present with arthritis, the ACPA response is generally increased in titre, uses more isotypes, displays a different glycosylation pattern, and are cross-reactive towards different citrullinated proteins (Fig. 1).

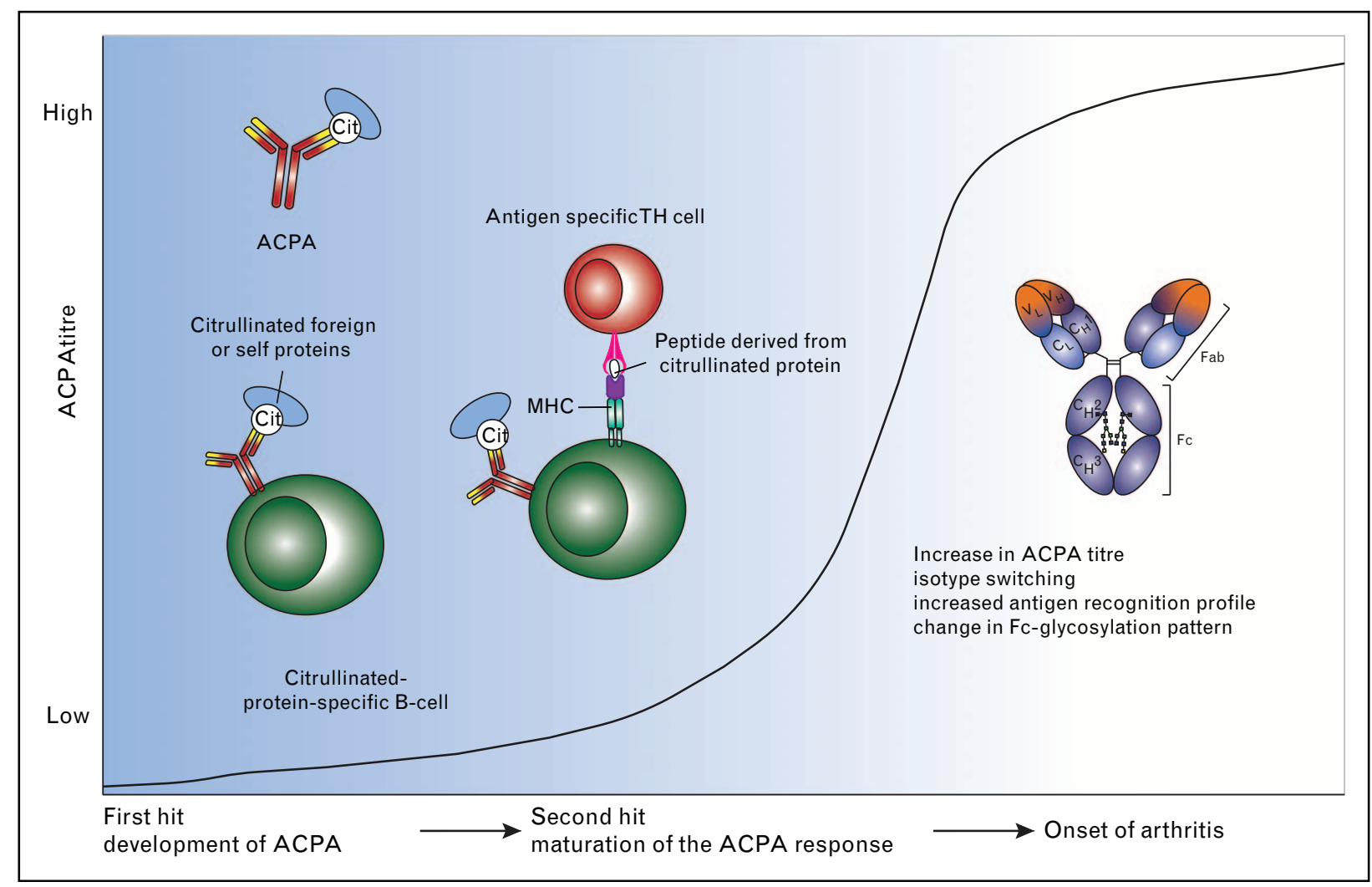

FIGURE 1. Maturation of the ACPA response. Antibodies reactive towards citrullinated proteins are already present in the preclinical phase of RA. Environmental triggers and epigenetic stochastic events are thought to play a role in the 'first hit', leading to the formation of ACPA. A 'second hit', such as an infection, triggers further expansion and maturation of the ACPA response. Once the disease manifests itself, the ACPA response is generally increased in titre, uses more isotypes, has a different glycosylation pattern, and an increased antigen-recognition profile towards various citrullinated proteins. Fab, fragment antigen-binding; $\mathrm{Fc}$, fragment crystallizable; $M H C$, major histocompatibility complex; $T_{H}, T$-helper cell. 


\section{HUMAN LEUCOCYTE ANTIGEN CLASS II ASSOCIATIONS IN RHEUMATOID ARTHRITIS}

The most important genetic risk factor for ACPApositive RA is the HLA class II region. RA, like many other autoimmune diseases, is characterized by a strong association with variants in the HLA class II region. These HLA associations differ in ACPApositive and ACPA-negative disease [32,33",34,35"], highlighting the complexity of pathogenic mechanisms underlying HLA associations in RA. The HLA class II region encodes for HLA-DR, HLA-DQ and HLA-DP proteins and is involved in antigen presentation to HLA class II restricted CD4 ${ }^{+}$T-helper cells. In 1976, analysis of mixed lymphocyte cultures from RA patients revealed that these individuals had certain HLA-DR4 molecules in common [36]. The HLA haplotypes that encode for the HLA-DR4 molecules were found to be characterized by the so-called 'HLAshared epitope (SE)', a common amino-acid sequence in the HLA-DRB1 chain [37]. Recent genome wide analysis revealed specific amino acids at positions 11 , 13, 71 and 74 of the HLA-DRB1 chain as well was single-amino-acid polymorphisms at position nine of HLA-B and HLA-DPB1 are associated with the greatest risk for RA [38]. Amino-acid positions 11 and 13 of HLA-DRB1 are among the most polymorphic and are highly relevant for the shaping of peptide-binding pockets located in peptide-binding groove of the HLA molecule. It is therefore not surprisingly that the statistically significant amino-acid positions are those involved in peptide presentation.

The HLA-SE alleles are now known to be specifically associated with ACPA-positive RA [32,38]. Conversely, HLA-DRB $1{ }^{*} 13$ alleles haplotypes have been found to protect against the development of ACPA-positive RA [33",34]. A possible explanation for the association of the 'HLA-shared epitope' with ACPA-positive RA might be that peptide presentation by the 'HLA-shared epitope' HLA molecules can facilitate the activation of $\mathrm{CD}^{+} \mathrm{T}$ cells which provide help to ACPA-producing B cells. In ACPApositive RA, ACPA are cross-reactive and bind to a wide variety of citrullinated self-proteins which indicates a loss of B-cell tolerance. However, it is unclear to what extent T-cell tolerance is lost. Identification of citrullinated epitopes recognized by autoreactive $\mathrm{T}$ cells in patients with RA has proven difficult. Analysis using peptide-HLA tetramers and in-vitro T-cell responses to candidate epitopes revealed T-cell recognition of several citrullinated epitopes in humans $\left[39,40,41^{*}, 42\right]$.

The HLA-DRB ${ }^{*} 13$ alleles which are protective for RA, carry a five amino-acid sequence called: DERAA. The DERAA sequence is also expressed by many microbes and in a self-protein vinculin. Citrullinated vinculin is expressed in the inflamed synovial membrane and was recently identified as a novel autoantigen for ACPA antibodies [43]. It is proposed that molecular mimicry of self-proteins with pathogenic microbial proteins might lead to a break of T-cell tolerance. Indeed, it was recently shown, that $\mathrm{T}$ cells present in HLA-DRB1*13negative donors were able to specifically recognize a DERAA-containing vinculin epitope that crossreact with DERAA sequences derived from pathogens [44"']. However, many $\mathrm{T}$-cell responses are absent in HLA-DR13+ donors, indicating the induction of DERAA-specific T-cell tolerance in these donors. Together, these studies suggests that the HLA class II locus can directly influence the maturation of the ACPA response via antigen-specific $\mathrm{T}$ cells, providing help to ACPA-producing B cells and enabling the maturation of the citrullinated protein-specific autoantibody response.

\section{PATHOGENIC ROLE OF THE IMIMUNE RESPONSE AGAINST CITRULLINATED PROTEINS}

Apart from the diagnostic application of ACPA as a biomarker, several clinical observations suggest that ACPA could play a direct role in disease pathology. First, ACPA may be found early in the course of disease, up to 7 years before RA manifests $[5,6]$. Second, various follow-up studies [45-47,48"] revealed that ACPA-positive patients with recentonset RA develop more bone erosions compared with ACPA-negative RA patients. Third, bone loss and reduced bone mineral density can be found in healthy ACPA-positive individuals, even before clinical onset of arthritis [49"].

Selective B-cell depletion using rituximab has been found to be effective in the treatment of RA $\left[50,51,52^{*}\right]$, providing evidence for the involvement of $\mathrm{B}$ cells in the pathogenesis of RA. ACPA-producing B cells are found to be enriched in synovial fluid $[21,53]$, which suggests that ACPA can be produced locally and directly contribute to synovial inflammation. Moreover, the numbers of ACPA-producing $B$ cells in the blood of RA patients correlate with ACPA serum levels [54].

Functional studies showed that immune complexes formed with ACPA mediate effector functions via Fc- $\gamma$ receptors [55], and can induce complement activation [24] and enhanced neutrophil extracellular trap formation [56]. In addition, there are reports that purified ACPA can induce osteoclastogenesis and bone resorption in mice [57], suggesting a direct link between ACPA and more 
severe joint destruction. So far, only two experimental studies succeeded in showing in vivo that ACPA may facilitate the transition from autoimmunity to inflammation. Transfer of antibodies specific to citrullinated fibrinogen [58] and transfer of antibodies targeting citrullinated-collagen [59] to mice with mild experimental arthritis led to disease exacerbation. It is interesting that no other positive data have been reported allowing that these two positive papers are similar as the many nonreplicated preclinical papers in other fields such as oncology [60].

RA patients receiving Abatacept show reduced levels of ACPA and rheumatoid factor in response to treatment [61"]. Moreover, a Swedish pharmacotherapy trial reported a decline of all ACPA levels independent of the clinical response on disease activity during the first 3 months of methotrexate treatment [17"']. However, effective treatment of established arthritis does not necessarily lead to reduced ACPA levels or a change in ACPA composition. For example, a Canadian cohort in early arthritis patients found that anti-CCP antibody fluctuations did not relate to clinical scores such as disease activity scores and the presence of erosions [62]. These findings suggest that autoantibody-producing B cells rather than the autoantibodies produced may be responsible for disease pathogenesis. Activated B cells secrete proinflammatory cytokines, such as interleukin-6 and TNF, and ACPA-producing B cells are found to be increased in the inflamed synovial membrane [16"].

In addition to ACPA, other autoantibodies and/ or autoantibody-producing $\mathrm{B}$ cells may also be involved in RA pathogenesis. Similarly to ACPA, both rheumatoid factor and anti-CarP antibodies are associated with disease severity and persistence $\left[8^{*}, 63^{*}, 64^{\prime \prime}\right.$. Anti-CarP autoantibodies recognize carbamylated proteins containing a homocitrulline, a posttranslational modification of lysine driven by cyanate, and can be found in patients with ACPAnegative RA. More recently, antibodies targeting another posttranslational modification, malondialdehyde/acetaldehyde (MAA) adducts, are found to be increased in RA patients and this antibody response is associated with the presence of ACPA [65"']. Similarly to carbamylation, MAA adducts are capable of the modification of a lysine. These findings raise the question why RA patients produce autoantibodies towards posttranslational modified proteins and whether these autoantibodies are implicated in disease pathogenesis. Further research is needed to confirm the current observations of anti-CarP antibodies in ACPA-negative and positive RA patients, and to determine whether these biomarkers can provide additional value next to the CCP2 test.

\section{CONCLUSION}

ACPA have proven to be a very useful biomarker for diagnosing RA and for predicting a severe disease course. Future investigations on the role of ACPA, other autoantibodies, and ACPA-producing B cells in RA may provide further insight in and understanding of the underlying disease pathogenesis. Follow-up studies of RA patients may provide useful information on the fluctuation of ACPA levels and changes in ACPA composition during disease progression and treatment. Together, these observations may allow new approaches to treat RA at an early, preclinical, stage of disease, and thus enable prevention of the transition of autoimmunity to inflammation and autoimmune disease.

\section{Acknowledgements}

None.

\section{Financial support and sponsorship}

Research in this report was supported by the FP7-project EUROTEAM as well as by the IMI-project BeTheCure.

\section{Conflicts of interest}

There are no conflicts of interest.

\section{REFERENCES AND RECOMMENDED}

\section{READING}

Papers of particular interest, published within the annual period of review, have been highlighted as:

- of special interest

-1. of outstanding interest

1. Vincent $C$, Serre G, Fournie B, et al. Natural lgG to epidermal cytokeratins vs IgG to the stratum corneum of the rat oesophagus epithelium, so-called 'antikeratin antibodies', in rheumatoid arthritis and other rheumatic diseases. J Autoimmun 1991; 4:493-505.

2. Schellekens GA, de Jong BA, van den Hoogen $\mathrm{FH}$, et al. Citrulline is an essential constituent of antigenic determinants recognized by rheumatoid arthritis-specific autoantibodies. J Clin Invest 1998; 101:273-281.

3. Vossenaar ER, Zendman AJ, van Venrooij WJ, Pruijn GJ. PAD, a growing family of citrullinating enzymes: genes, features and involvement in disease. Bioessays 2003; 25:1106-1118.

4. Aletaha D, Neogi T, Silman AJ, et al. 2010 rheumatoid arthritis classification criteria: an American College of Rheumatology/European League Against Rheumatism collaborative initiative. Ann Rheum Dis 2010; 69:1580-1588.

5. Rantapaa-Dahlqvist $\mathrm{S}$, de Jong BA, Berglin $\mathrm{E}$, et al. Antibodies against cyclic citrullinated peptide and $\lg A$ rheumatoid factor predict the development of rheumatoid arthritis. Arthritis Rheum 2003; 48:2741-2749.

6. Nielen MM, van Schaardenburg D, Reesink HW, et al. Specific autoantibodies precede the symptoms of rheumatoid arthritis: a study of serial measurements in blood donors. Arthritis Rheum 2004; 50:380-386.

7. Berglin $\mathrm{E}$, Johansson $\mathrm{T}$, Sundin U, et al. Radiological outcome in rheumatoid arthritis is predicted by presence of antibodies against cyclic citrullinated peptide before and at disease onset, and by IgA-RF at disease onset. Ann Rheum Dis 2006; 65:453-458.

8. Shi J, van de Stadt LA, Levarht EW, et al. Anticarbamylated protein (anti-CarP)

- antibodies precede the onset of rheumatoid arthritis. Ann Rheum Dis 2014; 73:780-783.

This article shows that anti-CarP antibody responses follow a similar evolution pattern as ACPA and rheumatiod factor, thereby indicating that there are similarities in the development autoantibodies associated with RA.

9. Terao $\mathrm{C}$, Ohmura $\mathrm{K}$, lkari K, et al. Effects of smoking and shared epitope on the - production of anticitrullinated peptide antibody in a Japanese adult population. Arthritis Care Res (Hoboken) 2014; 66:1818-1827.

This article shows that the HLA-SE alleles do not predispose to the initial development of ACPA, but rather to the development of ACPA-positive RA, thereby implying that the HLA-SE molecules play a role in the expansion of the ACPA response. 
10. van der Woude D, Rantapaa-Dahlqvist $S$, loan-Facsinay $A$, et al. Epitope spreading of the anticitrullinated protein antibody response occurs before disease onset and is associated with the disease course of early arthritis. Ann Rheum Dis 2010; 69:1554-1561.

11. loan-Facsinay $A$, Willemze $A$, Robinson $D B$, et al. Marked differences in fine specificity and isotype usage of the anticitrullinated protein antibody in health and disease. Arthritis Rheum 2008; 58:3000-3008.

12. van de Stadt $L A$, de Koning $M H$, van de Stadt RJ, et al. Development of the anticitrullinated protein antibody repertoire prior to the onset of rheumatoid arthritis. Arthritis Rheum 2011; 63:3226-3233.

13. van de Stadt $L A$, van der Horst $A R$, de Koning $M H$, et al. The extent of the anticitrullinated protein antibody repertoire is associated with arthritis development in patients with seropositive arthralgia. Ann Rheum Dis 2011; 70:128-133.

14. Brink M, Hansson M, Mathsson $L$, et al. Multiplex analyses of antibodies against citrullinated peptides in individuals prior to development of rheumatoid arthritis. Arthritis Rheum 2013; 65:899-910.

15. Rombouts $Y$, Ewing $E$, van de Stadt LA, et al. Anticitrullinated protein

I. antibodies acquire a pro-inflammatory Fc glycosylation phenotype prior to the onset of rheumatoid arthritis. Ann Rheum Dis 2015; 74:234-241.

This article indicates that ACPA acquire a distinct Fc glycosylation patterns around

3 months prior to onset of disease.

16. Koning F, Thomas R, Rossjohn J, Toes RE. Coeliac disease and rheumatoid

- arthritis: similar mechanisms, different antigens. Nat Rev Rheumatol 2015; $11: 450-461$.

This review gives on overview on the molecular mechanism underlying the development of coeliac disease and rheumatoid arthritis.

17. Kastbom A, Forslind $\mathrm{K}$, Ernestam S, et al. Changes in the anticitrullinated

- peptide antibody response in relation to therapeutic outcome in early rheumatoid arthritis: results from the SWEFOT trial. Ann Rheum Dis 2014; pii: annrheumdis-2014-205698. [Epub ahead of print]

A 2-year follow-up study of early RA patients reveals that disappearance of particular ACPA reactivities may be associated with a good treatment response in early RA.

18. van Beers JJ, Willemze A, Jansen JJ, et al. ACPA fine-specificity profiles in early rheumatoid arthritis patients do not correlate with clinical features at baseline or with disease progression. Arthritis Res Ther 2013; 15:R140.

19. Scherer HU, van der Woude $D$, Willemze A, et al. Distinct ACPA fine specificities, formed under the influence of HLA shared epitope alleles, have no effect on radiographic joint damage in rheumatoid arthritis. Ann Rheum Dis $2011 ; 70: 1461-1464$.

20. Fisher $B A$, Plant $D$, Brode $M$, et al. Antibodies to citrullinated alpha-enolase peptide 1 and clinical and radiological outcomes in rheumatoid arthritis. Ann Rheum Dis 2011; 70:1095-1098.

21. Amara $K$, Steen J, Murray $F$, et al. Monoclonal lgG antibodies generated from joint-derived $\mathrm{B}$ cells of RA patients have a strong bias toward citrullinated autoantigen recognition. J Exp Med 2013; 210:445-455.

22. Suwannalai $P$, Scherer $H U$, van der Woude $D$, et al. Anticitrullinated protein antibodies have a low avidity compared with antibodies against recall antigens. Ann Rheum Dis 2011; 70:373-379.

23. Suwannalai $P$, van de Stadt LA, Radner $H$, et al. Avidity maturation of anticitrullinated protein antibodies in rheumatoid arthritis. Arthritis Rheum $2012 ; 64: 1323-1328$

24. Trouw LA, Haisma EM, Levarht EWN, et al. Anti-cyclic citrullinated peptide antibodies from rheumatoid arthritis patients activate complement via both the classical and alternative pathways. Arthritis Rheum 2009; 60:1923-1931.

25. Anquetil $F$, Clavel $C$, Offer $G$, et al. $\lg M$ and $\lg A$ rheumatoid factors purified

- from rheumatoid arthritis sera boost the $\mathrm{FC}_{\mathrm{C}}$ receptor- and complementdependent effector functions of the disease-specific anticitrullinated protein autoantibodies. J Immunol 2015; 194:3664-3674.

This article describes the influence of $\lg M$ and $\lg A$ RF on the FCR and complementdependent effects of ACPA-immune complexes.

26. Suurmond J, Rivellese $F$, Dorjee $A L$, et al. Toll-like receptor triggering aug-

- ments activation of human mast cells by anticitrullinated protein antibodies. Ann Rheum Dis 2015; 74:1915-1923.

This article suggests that mast cells are important targets for TLR ligands and ACPA-immune complexes that can via mast cell activation enhance synovial tissue inflammation of RA patients.

27. Kokkonen $\mathrm{H}$, Mullazehi $\mathrm{M}$, Berglin $\mathrm{E}$, et al. Antibodies of $\lg \mathrm{G}, \lg \mathrm{A}$ and $\lg M$ isotypes against cyclic citrullinated peptide precede the development of rheumatoid arthritis. Arthritis Res Ther 2011; 13:R13.

28. van der Woude D, Syversen SW, van der Voort El, et al. The ACPA isotype profile reflects long-term radiographic progression in rheumatoid arthritis. Ann Rheum Dis 2010; 69:1110-1116.

29. Scherer HU, van der Woude D, loan-Facsinay A, et al. Glycan profiling of anticitrullinated protein antibodies isolated from human serum and synovial fluid. Arthritis Rheum 2010; 62:1620-1629.

30. Lundstrom SL, Fernandes-Cerqueira C, Ytterberg AJ, et al. IgG antibodies to

- cyclic citrullinated peptides exhibit profiles specific in terms of IgG subclasses, Fc-glycans and a Fab-peptide sequence. PLoS One 2014; 9:e113924.

This article shows that the Fc-glycan profile of both ACPA-IgG1 and ACPA-lgG4 are distinct, a feature which may affect ACPA effector and immune-regulatory functions in an IgG isotype-specific manner.
31. Karsten $\mathrm{CM}$, Kohl J. The immunoglobulin, IgG Fc receptor and complement triangle in autoimmune diseases. Immunobiology 2012; 217:10671079.

32. Huizinga TW, Amos $\mathrm{Cl}$, van der Helm-van Mil $A H$, et al. Refining the complex rheumatoid arthritis phenotype based on specificity of the HLA-DRB1 shared epitope for antibodies to citrullinated proteins. Arthritis Rheum 2005; 52:3433-3438

33. Oka S, Furukawa $H$, Kawasaki $A$, et al. Protective effect of the HLADRB1*13:02 allele in Japanese rheumatoid arthritis patients. PLoS One 2014; 9:e99453.

Association study in Japanese RA patients investigating the protective effects of DRB1 alleles.

34. van der Woude D, Lie BA, Lundstrom E, et al. Protection against anticitrullinated protein antibody-positive rheumatoid arthritis is predominantly associated with HLA-DRB1*1301: a meta-analysis of HLA-DRB1 associations with anticitrullinated protein antibody-positive and anticitrullinated protein antibody-negative rheumatoid arthritis in four European populations. Arthritis Rheum 2010; 62:1236-1245.

35. Han B, Diogo D, Eyre $S$, et al. Fine mapping seronegative and seropositive rheumatoid arthritis to shared and distinct HLA alleles by adjusting for the effects of heterogeneity. Am J Hum Genet 2014; 94:522-532.

Analysis of the association of individual amino-acid positions with ACPA-positive and negative RA.

36. Stastny P. Mixed lymphocyte cultures in rheumatoid arthritis. J Clin Invest 1976; 57:1148-1157.

37. Gregersen PK, Silver J, Winchester RJ. The shared epitope hypothesis. An approach to understanding the molecular genetics of susceptibility to rheumatoid arthritis. Arthritis Rheum 1987; 30:1205-1213.

38. Raychaudhuri S, Sandor C, Stahl EA, et al. Five amino acids in three HLA proteins explain most of the association between $\mathrm{MHC}$ and seropositive rheumatoid arthritis. Nat Genet 2012; 44:291-296.

39. Scally SW, Petersen J, Law SC, et al. A molecular basis for the association of the HLA-DRB1 locus, citrullination, and rheumatoid arthritis. J Exp Med 2013; 210:2569-2582.

40. Feitsma $A L$, van der Voort $E I H$, Franken KLMC, loan-Facsinay $A$ Identification of citrullinated vimentin peptides as T cell epitopes in HLADR4-positive patients with rheumatoid arthritis. Arthritis Rheum 2010; 62:117-125.

41. James EA, Rieck M, Pieper J, et al. Citrulline-specific Th1 cells are increased in

- rheumatoid arthritis and their frequency is influenced by disease duration and therapy. Arthritis Rheum 2014; 66:1712-1722.

This article shows that RA patients have higher frequencies of citrulline-specific $T$ cells.

42. Law SC, Street $\mathrm{S}, \mathrm{Yu} \mathrm{CHA}$, et al. T-cell autoreactivity to citrullinated autoantigenic peptides in rheumatoid arthritis patients carrying HLA-DRB1 shared epitope alleles. Arthritis Res Ther 2012; 14:R118.

43. van Beers JJ, Schwarte CM, Stammen-Vogelzangs J, et al. The rheumatoid arthritis synovial fluid citrullinome reveals novel citrullinated epitopes in apolipoprotein $\mathrm{E}$, myeloid nuclear differentiation antigen, and beta-actin. Arthritis Rheum 2013; 65:69-80.

44. van Heemst J, Jansen DTSL, Polydorides $S$, et al. Crossreactivity to vinculin

I. and microbes provides a molecular basis for HLA-based protection against rheumatoid arthritis. Nat Commun 2015; 6:6681.

This article describes that pathogen-induced DERAA-directed T cells cross-react with vinculin derived and microbial-derived DERAA epitopes in the context of protective/predisposing HLA alleles.

45. Courvoisier N, Dougados M, Cantagrel A, et al. Prognostic factors of 10-year radiographic outcome in early rheumatoid arthritis: a prospective study. Arthritis Res Ther 2008; 10:R106.

46. Syversen SW, Goll GL, van der Heijde D, et al. Prediction of radiographic progression in rheumatoid arthritis and the role of antibodies against mutated citrullinated vimentin: results from a 10-year prospective study. Ann Rheum Dis 2010; 69:345-351.

47. Plant $\mathrm{D}$, Thomson $\mathrm{W}$, Lunt $\mathrm{M}$, et al. The role of rheumatoid arthritis genetic susceptibility markers in the prediction of erosive disease in patients with early inflammatory polyarthritis: results from the Norfolk Arthritis Register. Rheumatology (Oxford) 2011; 50:78-84.

48. Jilani AA, Mackworth-Young CG. The role of citrullinated protein

antibodies in predicting erosive disease in rheumatoid arthritis: a systematic literature review and meta-analysis. Int J Rheumatol 2015; 2015:728610.

This meta-analysis showed that ACPA are strong predictors of joint erosions in RA.

49. Kleyer A, Finzel S, Rech J, et al. Bone loss before the clinical onset of

- rheumatoid arthritis in subjects with anticitrullinated protein antibodies. Ann Rheum Dis 2014; 73:854-860.

This article shows that structural bone damage starts before the onset of arthritis in healthy individuals with ACPA.

50. Cambridge $G$, Leandro MJ, Edwards JC, et al. Serologic changes following B lymphocyte depletion therapy for rheumatoid arthritis. Arthritis Rheum 2003; 48:2146-2154

51. Nakou M, Katsikas $G$, Sidiropoulos $P$, et al. Rituximab therapy reduces activated $B$ cells in both the peripheral blood and bone marrow of patients with rheumatoid arthritis: depletion of memory B cells correlates with clinical response. Arthritis Res Ther 2009; 11:R131. 
52. Trouvin AP, Jacquot $S$, Grigioni $S$, et al. Usefulness of monitoring of $B$ cell - depletion in rituximab-treated rheumatoid arthritis patients in order to predict clinical relapse: a prospective observational study. Clin Exp Immunol 2015; 180:11-18.

This prospective study suggests that monitoring of CD19 positive B cells could be useful to predict clinical replase in RA patients.

53. Snir $\mathrm{O}$, Widhe $\mathrm{M}$, Hermansson $\mathrm{M}$, et al. Antibodies to several citrullinated antigens are enriched in the joints of rheumatoid arthritis patients. Arthritis Rheum 2010; 62:44-52.

54. Kerkman PF, Rombouts $\mathrm{Y}$, van der Voort EIH, et al. Circulating plasmablasts/ plasmacells as a source of anticitrullinated protein antibodies in patients with rheumatoid arthritis. Ann Rheum Dis 2013; 72:1259-1263.

55. Laurent L, Clavel C, Lemaire $\mathrm{O}$, et al. Fc gamma receptor profile of monocytes and macrophages from rheumatoid arthritis patients and their response to immune complexes formed with autoantibodies to citrullinated proteins. Ann Rheum Dis 2011; 70:1052-1059.

56. Carmona-Rivera C, Khandpur R, Vivekanandan-Giri A, et al. Neutrophil extracellular traps are a source of citrullinated autoantigens and stimulate inflammatory responses in rheumatoid arthritis. Sci Transl Med 2013; 5:178ra40.

57. Harre U, Georgess D, Bang $\mathrm{H}$, et al. Induction of osteoclastogenesis and bone loss by human autoantibodies against citrullinated vimentin. J Clin Invest 2012; 122:1791-1802.

58. Kuhn KA, Kulik L, Tomooka B, et al. Antibodies against citrullinated proteins enhance tissue injury in experimental autoimmune arthritis. J Clin Invest 2006; 116:961-973.

59. Uysal H, Bockermann R, Nandakumar KS, et al. Structure and pathogenicity of antibodies specific for citrullinated collagen type II in experimental arthritis. J Exp Med 2009; 206:449-462.
60. Begley CG, Ellis LM. Drug development: raise standards for preclinical cancer research. Nature 2012; 483:531-533.

61. Scarsi M, Paolini L, Ricotta D, et al. Abatacept reduces levels of switched

- memory B cells, autoantibodies, and immunoglobulins in patients with rheumatoid arthritis. J Rheumatol 2014; 41:666-672.

This study describes the effects of Abatacept treatment on B lymphocytes in RA patients.

62. Barra L, Bykerk V, Pope JE, et al. Anticitrullinated protein antibodies and rheumatoid factor fluctuate in early inflammatory arthritis and do not predict clinical outcomes. J Rheumatol 2013; 40:1259-1267.

63. Humphreys J, Verheul M, Barton A, et al. Association of anticarbamylated

- protein antibodies with long-term disability and increased disease activity in patients with early inflammatory arthritis: results from the Norfolk Arthritis Register. Lancet 2015; 385 (Suppl 1):S44.

This article shows that anti-CarP antibodies are associated with long-term disability and increased disease activity in early arthritis patients.

64. Brink M, Verheul MK, Ronnelid J, et al. Anticarbamylated protein antibodies in

- the presymptomatic phase of rheumatoid arthritis, their relationship with multiple anticitrulline peptide antibodies and association with radiological damage. Arthritis Res Ther 2015; 17:25.

This study shows that the presence of anti-CarP antibodies is related with worse radiological progression independently of ACPA.

65. Thiele GM, Duryee MJ, Anderson DR, et al. Malondialdehyde-acetaldehyde

- adducts and antimalondialdehyde-acetaldehyde antibodies in rheumatoid arthritis. Arthritis Rheumatol 2015; 67:645-655.

This article shows that RA patients have increased autoantibodies against malondialdehyde-acetaldehyde adducts, another posttranslational protein modification, that are strongly associated with ACPA. 